\title{
Acciones colectivas territoriales en Chile, 2011-2013: de lo ambiental-reivindicativo al autonomismo regionalista
}

Esteban Valenzuela. Universidad Alberto Hurtado, Santiago, Chile. Francesco Penaglia. Universidad Alberto Hurtado, Santiago, Chile. Lía Basaure. Municipalidad de Maipú, Maipú, Chile.

RESUmen | Desde el año 2011 ha aumentado en Chile la conflictividad social, evidenciándose en un incremento de las acciones colectivas, donde las problemáticas regionales y locales han tenido mayor presencia en la vida política y en los medios. Sin embargo, si bien las ciencias sociales nacionales han dado cuenta del aumento de la conflictividad y constatado un nuevo ciclo de relaciones Estado-sociedad, existen escasas investigaciones sobre las particularidades de cada uno de los hechos que dan cuenta de tal transformación. El siguiente artículo busca avanzar en esa línea, caracterizando las principales acciones colectivas regionales desarrolladas desde 2011 . La hipótesis de trabajo que lo sustenta es que, al interior de un marco nacional de conflictos sociales regionales, cohabitan distintos fenómenos que no necesariamente apuntan a la trasformación social ni al establecimiento de un nuevo ciclo de relaciones Estado-sociedad; y que, pese a ello, se aprecia una politización de los movimientos territoriales en un proceso que va desde una demanda plural hacia un metarrelato anticentralista y en favor de una transformación que lleve a una mayor autonomía política y financiera de las regiones.

PALABras CLAVE | conflicto social, desigualdades regionales, descentralización.

ABSTRACT | In Chile, the last decade has led to an intensification of social conflict, evidenced by an increase in collective action. In this scenario, since 2011 various regional and local issues can be counted among those with a strongest presence in political life and the media, a process evidenced in collective actions. However, although national social sciences have described the escalation in conflicts and reported the existence of a new cycle of State-society relations, there is little research on the characteristics of each of the phenomena taking place along this line. The following article seeks to outline the main regional collective action developed since 2011, with the working hypothesis that within a national framework of regional social conflicts, different phenomena coexist that do not necessarily point to social transformation and the establishment of a new cycle of State-society relations. It is argued that, notwithstanding a politicization of local movements based on plural demands, this process is leading to an anti-centralist and grand narrative in favor of a transformation towards a greater political and financial autonomy of the regions.

KEY WORDS | social conflicts, regional inequalities, decentralization. 


\section{Introducción $^{1}$}

En este artículo se dará cuenta de la politización de movimientos regionalistas en Chile en el último decenio, a partir del análisis de conflictos que no pueden ser reducidos a un mero localismo defensivo ante un daño ambiental o a una lucha social anticapitalista o reivindicacionista, puesto que evidencian la construcción de discursos favorables a la autonomía política y a la coparticipación en los ingresos que se producen territorialmente. Los conflictos estudiados transitan de lo defensivo, puntual o sectorial, a luchas politizadas de más largo alcance (Castells, 2003). Ejemplo de ello es el caso de Calama, en que se yuxtaponen elementos de identidad ancestral y reinventada, pampina y atacameńa, con un grito plural de rabias que incluye tanto dimensiones de clase como identidades emergentes (Holloway, 2011). En los casos estudiados se observan discursos potenciados por la generación de riquezas que no quedan en el territorio, sin paquetes ni servicios de calidad (Organización para la Cooperación y el Desarrollo Económicos [OCDE], 2013), y que solo dejan externalidades negativas, como contaminación. En síntesis, se trata de un conjunto de movimientos que reclaman el derecho a ser ciudad (Lefebvre, 1969; Sabatini \& Wormald, 2004).

Al igual que Calama, los movimientos de Magallanes por mantener el precio del gas o el de Freirina por expulsar una megaempresa de carnes blancas generadora de malos olores, se inscriben no solo como motines de resistencia puntual: hay un giro creciente (no consolidado) hacia discursos politizados, que manifiestan que los males se deben a un modelo sociopolítico y económico centralista. Ante tal proceso, el artículo se hará cargo del crecimiento de los grupos territoriales que piden autonomía, especialmente en el extremo norte y sur del país. Para el análisis se ha optado por un enfoque híbrido, en el cual se integran miradas estructuralistas, marxistas y posestructuralistas, en torno al polisémico concepto de politización.

Esta noción, la de "politización", plantea uno de los principales problemas a la hora de caracterizar las acciones colectivas y movimientos sociales, puesto que adquiere diferentes connotaciones según sea el tipo de actores involucrados. Puede tratarse, entre otros, de grupos de interés, partidos políticos, organizaciones sociales, organizaciones no gubernamentales, cada uno de ellos con una agenda particular a la hora de participar. Para el estudio de la acción colectiva, es esencial considerar la diversidad intramovimiento y su discursividad, principalmente a la hora de explicar, por ejemplo, qué ha pasado en Chile a partir de 2011 con el conflicto social y el eventual "nuevo ciclo" entre Estado y sociedad al que se han referido diversos intelectuales (Mayol, 2013; Opplinger \& Guzmán, 2012; Garretón, 2013; Salazar, 2013). En este contexto, el estudio en profundidad de casos permite romper la categoría única de movimiento social o grupos en conflicto, para identificar particularidades y fenómenos únicos.

La investigación aquí presentada se sustenta en un trabajo de campo desarrollado entre mayo y noviembre de 2013, a través de cuarenta entrevistas en profundidad

1 Publicación asociada al proyecto Fondecyt número 1150684: "Movimientos Regionalistas y Transformaciones políticas en Chile 2011-2016: entre la cooptación y el poder autónomo”. 
a informantes calificados, dirigentes, políticos y líderes locales de Arica, Calama, Tocopilla, Copiapó, Aysén y Punta Arenas. El estudio tiene como objetivo principal caracterizar e identificar los relatos regionalistas manifestados en los movimientos sociales entre los años 2011 y 2013, relevando sus particularidades y principalmente el proceso de tránsito desde lo social reivindicativo hacia lo político. Para ello se privilegió la estrategia de estudio de casos, dadas las potencialidades de esta metodología para indagar fenómenos de causalidad compleja, en entornos reales y utilizando múltiples fuentes de información. En esta línea se recurrió, además de las entrevistas en profundidad, a indicadores cuantitativos y técnicas documentales (Martínez, 2006, p. 174).

La investigación llevada a cabo es de carácter descriptivo-exploratorio, y contempla -como se ha dicho- el estudio de casos múltiples, de carácter genérico ejemplar típico (Coller, 2005). Los seis casos seleccionados lo fueron a partir de cuatro criterios, según los cuales se trata de:

- acciones colectivas con discursos regionalistas;

- acciones colectivas con grados de estabilidad y procesos de socialización y articulación superior a cinco ańos;

- acciones colectivas con episodios conflictivos relevantes (paros regionales, tomas de terreno, cortes de ruta, marchas regionales);

acciones colectivas con presencia y relevancia mediática a nivel nacional.

Explícitamente se ha dejado fuera el movimiento mapuche, que amerita una mirada más amplia por su propia importancia y por el predominio en él de la cuestión étnico-nacional por sobre un proceso de descentralización con autonomía regional (Marimán, 2012; Tricot, 2013).

El artículo comienza con un desarrollo teórico, continúa con una caracterización histórica de las protestas regionales, para finalmente presentar los principales hallazgos de la investigación.

\section{Desde lo gregario a lo reivindicativo social y a lo político}

La construcción del orden social -parafraseando a Norber Lechner (1984) - es conflictiva y nunca acabada. Por esta razón, el orden resultante en un determinado contexto histórico y social es la expresión del poder hegemónico que establece estructuras, verdades y consensos (Gramsci, 1988; Foucault, 1979; Laclau \& Moffe 1986, Marx \& Engels, 2006); es decir, la dominación no solo se ejerce a través de la coerción, sino también desde el "sentido común", definido por Vico como "un juicio sin reflexión, universalmente experimentado por todo un grupo, por todo un pueblo, por el conjunto de una nación o por el conjunto de la raza humana" (citado en Nun, 1986, p. 203) ${ }^{2}$. Desde esta perspectiva, si bien todas las acciones colectivas conflictivas son portadoras de fisuras en el orden dominante, esto ocurre con 
distintos grados e intensidades. De esta manera, si bien "el grito" (Holloway, 2011) es un proceso de oposición y rechazo a lo existente, en muchos casos no representa un proyecto unificado desde lo político transformador, sino una expresión regresiva gregaria de defensa de intereses particulares y sectoriales.

El concepto de "movimiento social" es uno de los de más difícil delimitación dentro de las ciencias sociales, razón por la que, al revisar la literatura especializada, "no puede haber seguridad sobre que se estén dedicando al estudio de un mismo objeto de investigación” (Ravilla, 1996, p. 1). De hecho, un conjunto de fenómenos diversos es sometido a una misma categoría analítica (Santamarina, 2008; Garcés, 2012; Ramos, 1997). Para Arciga (2012), es posible sostener que "todo movimiento social es agente de conflicto, que vincula su acción opositora con la imagen de una comunidad que posibilita la realización del hombre, la concreción de la unidad nacional, la defensa del bien común, el libre desarrollo de las fuerzas productivas, etcétera" (p. 53). Es decir, en los términos de John Holloway (2011), se trata del "grito". Sin embargo, esta definición acotada es demasiado amplia desde el punto de vista fenomenológico, puesto que el "grito" como categoría de análisis puede referirse a distintos elementos. Al respecto, señala Penaglia (2014), la literatura establece distintos tipos de acciones colectivas:

De defensa egoista a intereses creados, los que, como acota Touraine (1997), "no constituyen nada más que acciones defensivas y son incapaces de dotar a su lucha de una significación general" (p. 100). Bajo esta categoría se pueden agrupar fenómenos como los NimBy - not in my back yard-, los cuales, para Amézaga y Martí (2012, p. 4 ), constituyen plataformas egoístas de defensa territorial en oposición a determinadas acciones públicas o privadas; por ejemplo, la construcción de un basural o una cárcel. Este tipo de acción colectiva no cuestiona el fondo del proyecto y no se opondría a la ejecución del proyecto en otro territorio; por tanto, no porta más que un rechazo primario centrado en el "nosotros" inmediato.

Por otro lado, también se puede constatar fenómenos de tipo caudillista, como el que Aldo Panfichi (2011) denomina "representación contenciosa”, caracterizada por acciones colectivas centradas en liderazgos locales o regionales (generalmente alcaldes o concejales), que crean plataformas personalistas para legitimarse a través de conflictos en que el oponente es el Estado central.

Defensas colectivas y aisladas, las que, si bien tienen una perspectiva social, no se conforman como proyecto en el largo plazo. En esta categoría se puede constatar lo que Scribano (2012) denomina "interdicción colectiva" (IC), caracterizada como "freno a las violencias, usurpaciones y desposesiones de lo que un(os) colectivo(s) designa(n) como compartido. En este sentido, las IC son acciones colectivas cuya intención central es prohibir la apropiación privada de un bien considerado común” (p. 30). También se pueden agregar las acciones de estallido, huelga o motín (Grez, 2007), que son principalmente aisladas, descoordinadas, de rebeldía primaria y sin proyecto de cambio social. 
De transformación social, esto es, acciones colectivas en las que, siguiendo a Touraine (1997), existe un "llamamiento al Sujeto, a la vez como libertad y como cultura, llamamiento que encontramos tanto en los movimientos de mujeres como en los que se preocupan por las minorías" (p. 100). Se caracterizan por una duración en su temporalidad y por la existencia de proyectos transformadores.

Más allá de la extensa discusión sobre el sujeto (véase, por ejemplo, Retamozo, 2009; Charry, 2006; Moriconi, 2009; Rauber, 2003; Tassin, 2012; Moreno, 2010; Arciga, 2012) e independientemente de la posición epistemológica -sea la adhesión a las perspectivas de sujetos históricos, o a las de sujetos heterogéneos, sujetos como proceso-, aun en las visiones más críticas se pueden encontrar acuerdos mínimos. De este modo, incluso ante la imposibilidad de cierre identitatario y de sujetos relativos en una pluralidad de posiciones con exceso de puntos de integración, se identifican procesos de unidad y articulación discursiva en los que no existe mera agregación, sino el establecimiento de mecanismos de solidaridad (Melucci, 1999). En esta línea, siguiendo a Moffe y Laclau (1986) "llamaremos articulación a toda práctica que establece una relación tal entre elementos, que la identidad de estos resulta modificada como resultado de esa práctica” (p. 142). Los autores agregan que "la práctica de la articulación consiste, por tanto, en la construcción de puntos nodales que fijan parcialmente el sentido; y el carácter parcial de esa fijación procede de la apertura de lo social, resultante a su vez del constante desbordamiento de todo discurso por la infinitud del campo de la discursividad" (p. 154).

Esta forma de acción puede ser realizada a través de frentes de masas (Salazar, 2011) caracterizados por una ideología, vanguardia y conducción política, o movimientos sociales caracterizados por espacios de autonomía, deliberación y soberanía. A su vez puede expresarse en estructuraras organizacionales tanto céntricas como rizomáticas (Faletti \& García, 2011), es decir, con énfasis en la unidad o en la diversidad. Por otro lado, a estas tres categorías movimientistas y sus diversas expresiones fenomenológicas, se podría agregar la existencia de grupos de presión e interés, los que en algunos casos plantean reivindicaciones ya sea individuales o colectivas (Jerez, 1997; Réserve, 2004) y redes transacionales de defensa, conformadas por ONG y organizaciones nacionales e internacionales movilizadas por causas comunes (Rivera, 2011; Toro, 2011). Estos fenómenos poseen la particularidad de que, si bien tienen una dimensión movimientista y de protesta, están ligados principalmente a organizaciones formales que buscan, como estrategia de acción, influir en la agenda pública y gubernamental, además del lobby y la inserción en el poder institucional.

En este contexto, si bien en Chile diversos intelectuales han constatado un aumento de la conflictividad social (véase Garretón, 2013; Salazar, 2011; Tironi, 2011; Mayol, 2012, sosteniendo la existencia de un "agotamiento", "fin" o "inflexión" del orden dominante dictatorial -neoliberalismo y amarres constitucionales-, nuestra hipótesis es que en las diferentes acciones colectivas regionales cohabitan distintos fenómenos, algunos con orientaciones mayoritarias de transformación social y otros con énfasis en la protección de intereses egoístas. 


\section{Antecedentes históricos de las expresiones regionalistas}

La totalidad de los movimientos estudiados se ha generado en las zonas del norte y sur del país, incorporadas a Chile con estatalidad recién desde 1870: en el Norte Grande, por anexión de los territorios bolivianos y peruanos, lo que no logró romper la identidad tarapaqueña, norteńa o pampina (González, 2010); y en el extremo austral aislado y despoblado (Martinic, 1992), a través de la pacificación violenta de los territorios mapuches (Marimán, 2012; Tricot, 2013), tras el fracaso del intento de mediación con el presidente Pérez en 1860-1861. Ha vencido una construcción estatal autoritaria con un nacionalismo liberal sustentado en la homogeneidad (Salazar, 1994 y 2005; Valenzuela, E., 1999). El resultado ha sido una expansión centralista excluyente de la identidad diversa de los nuevos territorios, a los cuales se les niega poder, autonomía política y participación relevante en la renta estatal (Rojas, 2013).

Para analizar la movilización territorial actual, se debe tener presente la histórica tensión entre autonomía regional y cooptación. En esta línea, el sistema político chileno, marcado por su centralismo presidencial, muestra una gran capacidad de permanencia desde el triunfo conservador-portaliano (1830) sobre federalistas y pipiolos liberales (Villalobos, 1989), que ha superado guerras civiles y protestas regionalistas no solo con coerción, sino también por la vía del uso de mecanismos de cooptación ${ }^{3}$ de disidentes al poder central. Esta construcción estatal centralista y desde arriba (Véliz, 1984; Góngora, 1981) ha debido sortear numerosas tensiones, entre las que destacan las que se señalan a continuación.

Las guerras civiles de 1851 y 1859, en que fueron derrotados los liberales-federalistas. Tras la derrota federalista y la tesis de asamblea provincial autónoma de José Miguel Infante (Salazar, 2006; Valenzuela, 2008), se impuso el gobierno centralizado que suprimió la autonomía regional e incluso los municipios, replicando el modelo monárquico-borbónico de la delegación por sobre los espacios de libertad que había construido el cabildo (Del Alcázar, 2006). La dureza de los decenios conservadores fue resistida en 1848 con los clubes de la igualdad y la libertad, que luego irrumpieron con fuerza en el levantamiento de 1851 uniendo a liberales, reformistas y federalistas e incluyendo la participación de nuevas capas sociales -artesanos, pequeños agricultores y profesores- en experiencias como el alzamiento en San Felipe y la toma de Talca en 1851 (Daitsman, 1995). Los hechos se agravaron ese ańo con la declaración del Atacama autónomo y constituyente, el ejército libre del norte, los tormentos públicos dictados por el intendente y el cansancio de los mineros respecto de la obligación de financiar incluso el tren a Caldera, ante la indolencia y centralismo capitalino (Bahamonde, 1977). El gobierno central resultó 
vencedor y ganó en la elite de poder una figura moderada como José Joaquín Pérez (1861-1871), quien en el decenio de 1860 realizó una apertura liberal que, si bien no repuso la asamblea provincial autónoma, al menos reinstauró los municipios e inició reformas políticas de mayor libertad de prensa y reunión. Entre ellas se incluyó una ley de amnistía para los cabecillas Pedro León Gallo y Manual Antonio Matta, los que se integraron al sistema de la mano del Partido Radical, sin cambios de fondo al régimen oligárquico (Vitale, 1971). Los sublevados abdicaron de la petición de autonomía y se hicieron parte del nacionalismo liberal centralista; los conservadores, por otro lado, promovieron el municipalismo como respuesta (Ley Irarrázaval, de comuna autónoma, de 1891), sin regiones fuertes (Illanes, 1993).

El desarrollismo industrial de las regiones en el Frente Popular como respuesta a la crisis del Estado oligárquico. La crisis del régimen oligárquico de 1924; la dictación de leyes sociales, el auge y caída del alessandrismo y el ibańismo; la depresión mundial agravada en Chile por la sustitución del salitre, acompañada de los experimentos socialistas de 1932, son algunos de los factores que concluyeron con una salida democrático-centralista e industrialista. Esta estuvo representada por el Frente Popular, que integró en alianza al Partido Radical, el Partido Socialista y el Partido Comunista, y solo a algunos de los grupos contestatarios locales, especialmente líderes regionalistas de Magallanes.

En la historiografía hay quienes resaltan que, desde 1938, el nuevo Frente Popular respondió a la división derechista y al desplazamiento a la izquierda del Partido Radical (Moulian, 2009), iniciando el tiempo de una república democrática, con políticas sociales pero con un alto nivel de centralización (Salazar, 2006). La visión regionalista destaca que movimientos como el magallánico empujaron hacia una visión más integral del territorio, con inversiones en zonas mineras para su industrialización y políticas dirigidas al desarrollo de zonas extremas (Martinic, 1992). Es así como sobrevino un ciclo de mayor inversión pública y fijación de polos de desarrollo (como el acerero en Concepción), pero sin fondos autónomos ni puesta en funciones de la "asamblea provincial" establecida en la Constitución de 1925, pero nunca reglamentada.

La izquierda se hizo estatista y no valoró la dispersión del poder; más bien, receló de la descentralización como un instrumento oligárquico al servicio de latifundistas que, mediante el clientelismo, controlaron los municipios. No obstante, los parlamentarios de centro (radicales y democratacristianos), al igual que muchos izquierdistas, calcaron las prácticas liberales-conservadoras de "gestionar proyectos" para "sus comunidades", sin una visión de descentralización y creación de fondos autónomos. Se instauró con ello el modelo parlamentario de brokers del poder, que lleva las demandas de sus territorios a Santiago (Valenzuela, A. 1977). Uno de los avances más importantes en el desarrollo regional fue la Ley $11828^{4}$, dictada en el

4 Se generaba un particular sistema de reparto: del $10 \%$ de las utilidades del cobre se depositaba el 75\% en el Banco Central, el 5\% en la Universidad Técnica del Estado, el 2\% a la Universidad Austral de Chile; entre el $18 \%$ y el $75 \%$ era destinado al fomento y progreso de las provincias productoras, y el 25\%, incluido en el presupuesto municipal (Penaglia \& Valenzuela, 2014, p. 9). Y desde 1955, un 4\% de las utilidades se empleaba para la reconstrucción de Calama. 
gobierno de Ibáñez, que "establecía un 50\% de las utilidades aplicado sobre el total de la producción, y una tasa variable del $25 \%$. En caso de que la producción bajara del $80 \%$ de la producción básica, el impuesto aumentaba en un 80\%" (Penaglia \& Valenzuela, 2014, p. 9)

Dictadura militar. La regionalización cuestionada en Chile fue decretada de manera tecnocrático-autoritaria en 1974, lo que venía gestándose en el desarrollismo cepaliano desde 1969 (Boisier, 1989). Se buscaba un mayor control social, y que la división regional favoreciera el orden y evitara la sublevación territorial. Se frenaron los avances en regionalización derogando la Ley 11828 y se sentaron las bases del modelo neoliberal, con la privatización de los servicios y de los recursos naturales.

Repartición de renta en el retorno regionalista pospinochetista. Los sectores regionalistas de la Concertación fueron minoritarios, por lo que siempre mantuvieron al margen el problema del centralismo a través de pequeños beneficios que lograron mantener en calma a las regiones y comunidades con más problemas. Luego, durante el gobierno de la Alianza por Chile estallaron los conflictos en Magallanes, Aysén y Calama, frente a los cuales se repitió el modelo de represión y negociaciones pragmáticas, sin autonomía relevante. A lo largo de la segunda década de gobiernos de la Concertación, y durante los dos primeros años del gobierno de Piñera (Alianza), se sucedieron protestas regionalistas. En algunas se demandaba la designación de ciertos territorios como regiones (Arica y Valdivia); en otras, regalías por sus recursos (Antofagasta-Calama), planes ante la pobreza y cesantía (Zona del Carbón, Atacama, Illapel), subsidios a los altos costos de energía y transporte en zonas extremas (Magallanes, Aysén, Tocopilla). Los gobiernos pospinochetistas controlaron el aparato estatal con sello paternalista y de distribución de cuotas de poder, asumiendo el modelo presicrático -presidencialismo centralista- del constitucionalismo pinochetista (Salazar, 2011; Valenzuela, 2007), lo que derivó en una crisis de legitimidad, representación y participación.

\section{El actual ciclo de las protestas territoriales}

Tres factores estructurales son actualmente el acicate de la protesta territorial: el agotamiento del modelo centralista, la crisis del capitalismo y del modelo neoliberal concentrador-extractivista, y la crisis de representación de los partidos tradicionales.

El agotamiento del modelo centralista, que perpetúa desigualdades y crea resentimiento en las regiones cuando se comparan con el auge de la zona metropolitana de Santiago, la cual concentra el 40\% de la población y el 50\% del PIB, es el principal aguijón tras el descontento regional. La propia protesta mapuche se funda en la demanda por recuperar la autonomía territorial, poder y territorios libres (Lewis, 1994; Marimán, 2012).

En la tabla 1 podemos observar que la Región Metropolitana incrementó su población en 1 millón de personas aproximadamente en la década de 1992 a 2002, y entre 600.000 y 700.000 personas en la década de 2002 a 2012. Sin embargo, el PIB aumentó exponencialmente, pasando de los 2.174.295 millones en 1992, a los 
16.199.205 en 2002 y finalmente a 48.802.068 en el año 2012. Ello demuestra la alta concentración del PIB en la Región Metropolitana, que claramente no está en relación con el aumento de su población.

TABLA I | PIB regional a precios constantes año 1992, 2002 en millones, y a precios del año anterior encadenado 2012 en miles de millones de pesos 1986/Población censos 1992, 2002, y 2012

\begin{tabular}{|c|c|c|c|c|c|c|c|}
\hline & \multirow{2}{*}{ REGIÓN } & \multicolumn{2}{|c|}{1992} & \multicolumn{2}{|c|}{2002} & \multicolumn{2}{|c|}{2012} \\
\hline & & POBLACIÓN & PIB & POBLACIÓN & PIB & POBLACIÓN & PIB \\
\hline XV & \begin{tabular}{|l} 
Arica y \\
Parinacota
\end{tabular} & 174.119 & & 189.644 & & 213.595 & 626.582 \\
\hline I & Tarapacá & 165.460 & 155.991 & 238.950 & 1.146 .401 & 298.257 & 1.459 .018 \\
\hline II & Antofagasta & 410.724 & 316.527 & 493.984 & 2.619 .098 & 542.504 & 10.462 .998 \\
\hline III & Atacama & 230.873 & 92.902 & 254.336 & 644.260 & 290.581 & 2.737 .650 \\
\hline IV & Coquimbo & 504.387 & 128.413 & 603.210 & 729.281 & 704.908 & 3.189 .807 \\
\hline V & Valparaíso & 1.384 .336 & 426.711 & 1.539 .852 & 3.072 .320 & 1.723 .547 & 8.037 .889 \\
\hline $\mathrm{RM}$ & $\begin{array}{l}\text { Región } \\
\text { Metropolitana }\end{array}$ & 5.257 .937 & 2.174 .295 & 6.061 .185 & 16.199 .205 & 6.683 .852 & 48.802 .068 \\
\hline VI & O'Higgins & 696.369 & 231.712 & 780.627 & 1.547 .509 & 872.510 & 4.487 .868 \\
\hline VII & Maule & 836.141 & 206.944 & 908.097 & 1.296 .565 & 963.618 & 3.678 .518 \\
\hline VIII & Biobío & 1.734 .305 & 460.894 & 1.861 .562 & 3.268 .213 & 1.965 .199 & 7.925 .369 \\
\hline IX & La Araucanía & 781.242 & 115.176 & 869.535 & 914.957 & 907.333 & 2.234 .719 \\
\hline XIV & Los Ríos & 329.925 & & 356.396 & & 36.3887 & 1.219 .438 \\
\hline $\mathrm{X}$ & Los Lagos & 618.884 & 180.081 & 716.739 & 1.708 .070 & 785.169 & 2.465 .240 \\
\hline XI & Aisén & 80.501 & 20.961 & 91.492 & 213.608 & 98.413 & 473.734 \\
\hline XII & $\begin{array}{l}\text { Magallanes y } \\
\text { de la Antártica }\end{array}$ & 143.198 & 122.652 & 150.826 & 473.745 & 159.102 & 860.528 \\
\hline
\end{tabular}

FUENTE BANCO CENTRAL DE CHILE Y CENSOS I992, 2002, 2012

LAS REGIONES XV Y XIV NO TIENEN SUS DATOS DE PIB DESGLOSADOS PARA I992 NI PARA 2002.

La crisis del capitalismo y del modelo neoliberal concentrador-extractivista constituye un segundo factor que ha generado en todo el continente un ciclo de protesta social contra el daño ambiental, la pobreza y falta de empleos de calidad, la ausencia del Estado y la corrupción (Acosta, 2012).

Si bien la crisis económica internacional no tuvo fuertes impactos en Chile-debido al crecimiento de China y el alto precio del cobre hasta el 2012-, desde entonces sí ha aumentado el malestar social. En esta línea, como señala Penaglia (2012), entre las numerosas hipótesis explicativas del conflicto se encuentra la gran desigualdad social y económica existente en Chile, la que aumentaría la frustración de expectativas o privación relativa. De este modo, un aumento en indicadores macroeconómicos sin un incremento real en el bienestar de los grupos bajos y medios, generaría un distanciamiento entre la realidad mediática de una elite económica y política, con respecto a la realidad del resto de la población. Blofield (2011) señala al respecto que "las clases más bajas tienden a estar expuestas constantemente al estilo de vida de las clases media y alta a través de la televisión, que es omnipresente” (p. 4). Esta circunstancia, como 
sostiene Tironi (2008), se constituye en una "bomba de tiempo", ya que la mayoría de la población se relaciona con un mundo lujoso y ostentoso que no le es propio 5 . Como consecuencia de lo anterior, en las regiones crece un malestar social que se traduce en protestas y estallidos sociales, fenómenos que se han gestado en territorios postergados por el poder central (crisis de expectativas entre lo nacional y lo regional). Ello ocurre incluso en territorios cuya situación socioeconómica no es inferior a la nacional, pero cuyo desarrollo no refleja sus riquezas. Tal desequilibrio los lleva a sentirse desfavorecidos por el sistema impositivo y por las consecuencias negativas de las actividades económicas, como inflación y contaminación. Se trata, así, de una crisis de expectativas entre el potencial económico de una región y su desarrollo real.

La tabla 2 sintetiza las diferencias salariales corregidas por poder de compra, lo que permite ilustrar las desigualdades territoriales (sea por postergación o por desarrollo económico inequitativo).

TABla 2 Ingresos salariales. Promedio mensual por región de Chile, ajustado al poder de compra regional (PCR) en miles de pesos 2013

\begin{tabular}{|l|l|l|}
\hline \multicolumn{1}{|c|}{ REGIÓN } & NOMINAL & AJUSTADO POR PCR Y CALIFICACIÓN \\
\hline Arica y Prinacota & 594 & 535 muy bajo \\
\hline Tarapacá & 713 & 570 bajo \\
\hline Antofagasta & 914 & 730 alto \\
\hline Atacama & 777 & 630 promedio \\
\hline Coquimbo & 656 & 590 bajo \\
\hline Valparaíso & 594 & 594 bajo \\
\hline O’Higgins & 563 & 563 bajo \\
\hline Maule & 487 & 487 muy bajo \\
\hline BíoBío & 573 & 573 bajo \\
\hline Araucanía & 494 & 494 muy bajo \\
\hline Los Ríos & 498 & 498 muy bajo \\
\hline Los Lagos & 519 & 519 muy bajo \\
\hline Aysén & 591 & 530 muy bajo \\
\hline Magallanes y Antártica & 643 & 580 bajo \\
\hline Región Metropolitana & 659 & 659 alto \\
\hline Promedio país & 627 & 627 \\
\hline
\end{tabular}

FUENTE INGRESO PROMEDIO DE COTIZACIÓN PREVISIONAL DE HOMBRES POR REGIÓN, SEPT. 20 I 3. SUPERINTENDENCIA DE PENSIONES. SE CALCULA EL PCR (COSTO MAYOR EN SERVICIOS BÁSICOS, VERDURAS/FRUTAS, VIVIENDA) EN UN 20\% EN TARAPACÁ, ANTOFAGASTA Y ATACAMA, Y IO\% EN ARICA Y PARINACOTA (MAYOR DISPONIBILIDAD DE HORTALIZAS Y SERVICIOS, TACNA), COQUIMBO, AYSÉN Y MAGALLANES (MAYOR SUBSIDIO GAS)

5 No obstante -para bien o para mal-, esta desigualdad puede mantenerse sin provocar "estallidos sociales" cuando los países son capaces de generar expectativas de "progreso y movilidad social" (Tironi, 2008, p. 51). Tal fenómeno ocurre, por ejemplo, en Estados Unidos, donde cohabitan marginalidad y desigualdad sin grandes niveles de conflicto social, ya que se ha creado la imagen o ilusión de que "América es el país de las oportunidades" y que a través del esfuerzo individual es posible progresar. Como señala Solimano (2010), “de la gente se deriva la percepción de vivir o no en un orden social justo, donde las oportunidades son percibidas como razonablemente iguales para todos, donde la capacidad de esfuerzo individual y colectivo, el talento, la inventiva y la actitud frente al riesgo son los determinantes fundamentales de la capacidad de progreso económico y de generación de ingresos de las personas" (p. 9). 
La crisis de representación de los partidos tradicionales. Transformados en elites oligárquicas asentadas en la metrópoli (Aid Camp, 2000; Espinoza, 2010), ya no representan los intereses del territorio, lo que ha generado incapacidad para canalizar las demandas ciudadanas. En estas circunstancias, como señala Latinobarómetro (2011), gran parte de los conflictos sociales actuales son portadores de demandas dirigidas a gobiernos "democráticos" que muestran incapacidad para gobernar para la mayoría y mejorar la distribución de la riqueza (p. 7). Destacan, además, la debilidad institucional y la incapacidad de generar constructivismo político, sea por la elitización de los gobernantes (Michels, 1962); por la existencia de enclaves autoritarios que imposibilitan las transformaciones sociales (Garretón, 2002); o por una pérdida en la cadena de equivalencias entre actores, necesidades y trasformaciones (Panizza, 2009), lo que generaría una ruptura entre sociedad y Estado (Garretón, 2013). Con ello, como señala Cavarozzi (2006), la ineficiencia estatal alimenta su deslegitimidad. El resultado es que, junto con mayores movimientos sociales, se observan fenómenos electorales que evidencian el malestar. Tal como muestran las tablas 3 y 4 , en las zonas extremas y más movilizadas se ha generado más del 90\% de las rupturas del sistema binominal, con la elección de parlamentarios fuera del duopolio Alianza-Concertación (Nueva Mayoría), a la vez que los alcaldes independientes dominan las grandes ciudades del norte.

TABLA 3 Parlamentarios independientes por fuera de grandes coaliciones, 2002-2013

\begin{tabular}{|l|l|}
\hline \multicolumn{1}{|c|}{ ZONA } & \multicolumn{1}{c|}{ PARLAMENTARIOS } \\
\hline Arica & Rosa González, Vlado Mirosevic \\
\hline Iquique & Jorge Soria, Marta Isasí \\
\hline Antofagasta & Pedro Araya \\
\hline Coquimbo & Pedro Velásquez \\
\hline Illapel & Luis Lemus \\
\hline Colchagua & Alejandra Sepúlveda \\
\hline Punta Arenas & Carlos Bianchi, Miodrag Marinovic, Gabriel Boric \\
\hline
\end{tabular}

FUeNTE DATOS ObTenidos Del SERVicio Electoral (SERVEL), Chile

TABLA $4 \mid$ Alcaldes alternativos al duopolio en ciudades de más de 20.000 habitantes en el norte de Chile

\begin{tabular}{|l|l|l|}
\hline \multicolumn{1}{|c|}{ CIUDAD } & \multicolumn{1}{c|}{ ALCALDE } & \multicolumn{1}{c|}{ MILITANCIA } \\
\hline Arica & Salvador Urrutia & Independiente cercano al Partido Progresista de Chile (pro) \\
\hline Iquique & Jorge Soria & Fuerza del Norte \\
\hline Antofagasta & Karen Rojo & Independiente de derecha \\
\hline Tocopilla & Fernando San Román & Independiente cercano al pro \\
\hline Calama & Esteban Velásquez & Independiente cercano al Pro \\
\hline Copiapó & Mario Gicardini & Independiente (ex Partido Socialista) \\
\hline
\end{tabular}

FUENTE DATOS OBTENidos DEL SERVicio ELECTORAL (SERVEL), CHILE 


\section{Movimientos territoriales en Chile, análisis de casos}

\section{Regionalismo en pos de beneficios económicos:}

\section{Arica, movilización débil en aumento}

Los ariqueños tienen identidad geopolítica como frontera norte de Chile, lugar de permanente tensión histórica con los vecinos y "rabia" ante la pérdida de los beneficios con que contaba desde 1953 bajo el régimen de Puerto Libre, y luego como polo industrial con armadurías de autos, y que perdió con la creación de una zona franca en Iquique. Esta sensación de despojo recrudeció con el auge de Tacna e Iquique en las últimas décadas, en comparación con el estancamiento socioeconómico de Arica.

Los ariqueños demandan mayores posibilidades económicas. Por ejemplo, Hermann Mondaca Raiteri, líder de la Corporación Ciudadanía Activa, denuncia que Iquique puso trabas al anexo de la zona franca instalada cerca del Aeropuerto de Chacalluta en Arica: "No funciona porque solo tiene ventajas tributarias; acá se le agrega un valor a los productos que se venden o exportan, por lo cual hay solo tres empresas y no entran ni los gatos" (Hernán Mondaca Raiteri, exalcalde de Arica, entrevista realizada en Arica en septiembre de 2013).

El dirigente de la Red Arica, Vlado Mirosevic (elegido diputado por la zona), levantó en su plataforma la demanda de devolución a Arica de $50 \%$ de lo que recauda el estado central en ventas en la Región de Arica y Parinacota, lo que implica una dimensión más politizada de cambio estructural en favor de las regiones. Además Mirosevic firmó el texto de la Coalición Regionalista, liderado por los regionalistas federalistas y autonomistas en junio del año 2013: "Nuestra demanda es política para dar autonomía a las regiones con el ideario de José Miguel Infante, a quien hemos rescatado en el Partido Liberal. El norte se está moviendo, hay alcaldes independientes y progresistas en Arica, Iquique, Calama, Tocopilla, Copiapó, y pronto reuniremos fuerza política común para transformar Chile. Dicho cambio no es solo elegir intendentes; se necesitan recursos, devolución de lo que generamos y autonomía en temas claves, como el uso del agua. Tacna riega sus parques, y es un vergel, reutilizando el agua tratada. Acá en Chile no tenemos autonomía" (entrevista realizada en Arica en septiembre del año 2013).

Podemos darnos cuenta, en el caso de Arica, de que el problema de centralización tiene múltiples aristas. No solo genera desigualdad en la lógica bilateral Santiago-regiones, sino que también incentiva la competencia y la rivalidad entre las mismas regiones (interregional) cuando se trata de la búsqueda de recursos del gobierno central. Así, además de contener elementos como la postergación y aislamiento, evidencia la incapacidad del Estado para resolver conflictos. En esta línea, como señala Klein (2005), "el desarrollo local ha perdido algunos de los principios que constituían su base. Los objetivos de justicia y de equidad son a menudo relegados por la idea del empoderamiento de regiones y lugares, con el fin de que estas puedan competir con éxito en una economía abierta. Esto tiene como resultado la exacerbación de la competencia entre colectividades locales por atraer recursos públicos o privados cada vez más escasos" (p. 31).

El año 2013, a través de una asamblea ciudadana con participación de más de un centenar de personas, se levantó el movimiento social "Asamblea ciudadana por 
la dignidad y la vida en Arica" para exigir el cierre del proyecto minero de manganeso Los Pumas, que se instalaría en el cerro Chuńo, sector del valle de Lluta, contaminando la agricultura del valle y las aguas de la ciudad. Asimismo, continuó manifestándose el rechazo a la termoeléctrica Parinacota-Cerro Chuño, y se plantearon demandas tales como la expulsión definitiva de toda empresa agroindustrial transgénica desde los valles de la zona, la instauración de un nuevo plan de desarrollo regional con la participación plena y efectiva de la ciudadanía y en el cual se considerara el turismo, la agricultura orgánica y el desarrollo de energías limpias.

En este contexto, se desplegaron distintas marchas, paralización regional, y cortes en las rutas que van hacia Perú, Bolivia y al aeropuerto, aumentando el número de participantes, la densidad de las redes, la regularidad de las acciones y la politización de las demandas.

\section{Atacama: de la memoria histórica a la lucha territorial actual}

La Región de Atacama ha tenido tres dimensiones de alta movilización territorial, que la empoderaron en la primera década del siglo xxi:

- El rescate de la memoria histórica del poderío de Atacama y su Revolución Constituyente de 1859, forjado por intelectuales (el Grupo del Museo Regional), empresarios mineros (Jonás Gómez) y políticos regionalistas ${ }^{6}$.

- Los movimientos territoriales-étnicos con demandas ambientales contra empresas (mineras, termoeléctricas y faenadoras).

- La corriente regionalista en política, con la emergencia de actores independientes y regionalistas.

En este contexto, luego de la aprobación del Estudio de Impacto Ambiental del proyecto binacional PascuaLama (Chile-Argentina) elaborado por la trasnacional Barrick Gold (Rivera, 2010; Fuenzalida \& Quiroz, 2012), se comenzaron a articular distintas redes indígenas y vecinales, como el comité Valle de Huasco, junto con la participación de organizaciones ambientales nacionales e internacionales ${ }^{7}$, que llevaron a la creación de una red trasnacional de defensa contra Barrick Gold ${ }^{8}$.

6 En 1999 se sacó del baúl del olvido a los héroes de las rebeliones regionalistas encabezadas por el norte de Chile en 1851, y sobre todo en 1859, con la toma de Copiapó por Pedro León Gallo, los Matta y el artesano (exmilitar) Pedro Pablo Zapata. Convergieron entre 1999 y 2002 el rescate de la bandera de fondo azul con una estrella amarilla que enarbolaron los subversivos de Atacama cuando pidieron una nueva Constitución, la elección de intendentes y la entrega a las provincias de una parte significativa de los impuestos mineros que producían. El alcalde Cicardini, de Copiapó, aventura: "Nuestro despertar es completo y no descansaremos en la alianza de treinta municipios mineros, en coordinación con Calama, hasta que logremos una parte relevante de los royalties mineros para nuestras zonas. Esa fue la lucha de los atacameńos el 59 y sigue viva”.

7 A nivel nacional participaron ong ambientalistas, como el Observatorio Latinoamericano de Conflictos Ambientales, el Instituto de Ecología Política, Oceana y Chile Sustentable; mientras que a nivel internacional destaca la red internacional Protest Barrik/protestbarrick.net (Western Shoshone Defense Project; Mining Watch Canada; Mines and Communities, Friends of the Earth, Australia; Save Lake Cowal Campaign; Rainforest Information Center; Cyanide Watch; OLCA, Valley Downstream Alliance; y el Grupo No a Pascua Lama, Montreal) (Rivera, 2011).

8 La red trasnacional ha tenido campañas y protestas en Chile, Argentina, Perú, Australia, Canadá, Filipinas, Tanzania, entre otros países. 
Los temas étnicos, ambientales y ciudadanos convergieron en torno a la problemática del agua y la contaminación, creándose alianzas entre profesionales, indígenas, agricultores, artesanos y productores. Se forjó así una sociedad civil de luchas contra la minería y el modelo extractivista de desarrollo, por la recuperación del agua y contra las compensaciones cooptativas del poder central, lo cual fue generando una paulatina politización de las demandas. Como señaló en una entrevista Rodrigo Villablanca:
Yo soy de la comunidad de Sierra Huachacán, en el valle de San Félix, bien al inte- rior, cerca de PascuaLama. En este valle hay tres comunidades diaguitas. Por el valle de El Tránsito hay unas quince comunidades más. Se ha tratado de hacer una reet- nificación, nosotros perdimos la lengua kakán que usaron nuestros antepasados, por todas las matanzas, el mestizaje y las leyes que prohibieron el uso de nuestra lengua. Somos los últimos que vamos quedando de una cultura milenaria, que por razones históricas ha sido diezmada y destruida. Acá hay una comunidad agrícola, los huascoaltinos, que son descendientes directos de los antiguos diaguitas, pero han tenido hartos problemas con las mineras que se meten en su territorio. En Chile la ley minera está por sobre cualquier otra: entran, hacen caminos, toman los terrenos, y a las comunidades no les queda otra que judicializar los temas. (Rodrigo Villablanca, líder diaguita contra Pascua Lama y presidente del Comité Ecológico y Cultural "Esperanza de Vida"; entrevista realizada en septiembre del año 2013)

A través de la movilización de la comunidad y de una red de organizaciones, principalmente ambientalistas, se logró la paralización del proyecto PascuaLama, con el "Movimiento socioambiental valle del Huasco" como el mayor articulador de las demandas regionales. Algo parecido sucedió en Freirina, con un movimiento fundado sobre las bases y redes de movimientos anteriores. En esta ocasión, la comunidad, sobrepasada por la contaminación y los malos olores de la planta faenadora de cerdos Agrosuper, consiguió el cierre definitivo de una de las plantas faenadoras más grandes de Chile, recurriendo para ello a cortes de rutas, barricadas y enfrentamientos con carabineros.

\section{Calama: alto precio del cobre sin beneficios en el territorio}

Calama constituye uno de los casos paradigmáticos de privación relativa y crisis de expectativas intraterritoriales. Como señala el alcalde Esteban Velásquez, "en los últimos cinco ańos Codelco Norte Calama ha generado 18.000 millones de dólares de utilidades, y de eso, cero peso queda en la comuna de Calama (...). No queremos quedarnos con todo, por supuesto, ni con la mitad, sino con un pequeño porcentaje, porque las externalidades y todas las cosas negativas las vivimos aquí en Calama” (Esteban Velásquez, alcalde de Calama, entrevista realizada en septiembre del ańo 2013 en Calama). Con tal postura se reivindica el restablecimiento de los principios de la Ley 11828, derogada por la dictadura militar, que dejaba parte de las utilidades mineras en las comunas, favoreciendo el desarrollo local.

En este contexto, en agosto de 2009 se desarrolló el primer cabildo con la participación de organizaciones, sindicatos y gremios, realizándose posteriormente las primeras manifestaciones públicas bajo el eslogan "Qué sería de Chile sin Calama”. 
Con un petitorio de cinco puntos firmado por 40.000 personas, en septiembre de 2009 los representantes de las organizaciones viajaron a Santiago para presentar las siguientes demandas:

- La recuperación del 5\% de las utilidades del cobre en zonas productoras.

- Compensación por el traslado del campamento de Chuquicamata a Calama.

- Declaración de Calama como Zona Extrema.

- Compensación de 400 millones de dólares por los 34 años en que la ciudad no ha contado con las utilidades del cobre.

- Renacionalización del cobre y del agua.

Ante la falta de respuesta, o respuestas insatisfactorias por parte del gobierno, desde la fecha y durante más de tres años en Calama se han desarrollo distintas manifestaciones y paros regionales. A su vez, como un mecanismo de articulación, con el liderazgo de Esteban Velásquez se ha creado la Asociación de Municipios del Norte, la cual agrupa a diferentes alcaldes que, cansados del centralismo, han comenzado a realizar acciones conjuntas.

\section{Tocopilla: del rechazo frente a la lenta reconstrucción posterremoto,} a la acción anticentralista

Si bien las protestas de Tocopilla a mediados del año 2013 explotaron puntualmente por la imposición de una planta automatizada de revisión técnica, que obligaría a los taxis colectivos a estándares impensados en una zona abandonada con calles en pésimo estado, los factores de largo plazo se relacionan con el resentimiento por la pobre reconstrucción posterremoto 2007. A la fecha persistían colegios en malas condiciones en que las clases se habían estado dictando en containers durante más de cinco años. Continuaban la inexistencia de recursos, a pesar de tener las centrales térmicas en medio de la ciudad; los problemas en salud, debido a la ausencia de médicos especialistas, lo que obligaba a realizar viajes de al menos cinco horas en casos de requerirse atención, entre otros factores.

El claro agotamiento de las vías institucionales y la falta de respuesta de las autoridades ante estos problemas, llevaron a formar una asamblea ciudadana donde participaron dirigentes sociales de toda índole: estudiantiles, sindicales (taxi-colectivo), de la unión comunal de juntas de vecinos, unión comunal de padres y apoderados, ciudadanos y ciudadanas de base, y el alcalde de Tocopilla, Fernando San Román. Los actores acordaron una jornada de paralización el día 1 de agosto de 2013, en que más de 10.000 personas se juntaron en las calles. Se realizaron, además, cortes de ruta, barricadas, toma del puente de Tocopilla, todo lo cual generó una fuerte represión por parte de Fuerzas Especiales de Carabineros.

Con el correr del tiempo, el discurso de los líderes sociales pasó de ser reivindicativo peticionista a altos grados de politización anticentralista: "Independientemente de la reivindicación inmediata, estoy absolutamente convencido de que hay que formar una fuerza política autónoma y se está tratando de aglutinar a los movimientos sociales y liderazgos de la región, independientemente de su militancia política... 
Queremos descentralización, regionalismo, autonomía, estamos aburridos de que todo lo decida Santiago y que todos los recursos se vayan a Santiago" (Fernando San Román, 2013).

El dirigente estudiantil Jean Pierre Vilches, en entrevista realizada en 2013, señalaba que los problemas principales que vive Tocopilla son el centralismo y la desigualdad. Y con un discurso un poco más radical, Mariza Pino, dirigente del movimiento "Tocopilla vuelve", señalaba: "Ya sea este gobierno o el gobierno que venga, tenga cuidado, porque Chile se divide de la Iv Región para acá... Yo desde que soy dirigente que vengo diciendo que nosotros, cerrando la Iv Región para acá, se divide Chile. Nosotros hacemos un segundo Chile y Chile de allá va a ser pobre" (Maritza Pino, 2013).

\section{Aysén: politización reformista ascendente y redes transversales}

El conflicto en Aysén se desató en un contexto de baja en la industria del salmón y de la pesca. Esto provocó el malestar de los pescadores, que, junto a dirigentes de la zona, el día 7 de febrero de 2012 se tomaron el puente Presidente Ibáńez, principal acceso a Puerto Aysén por la vía terrestre. Seis días más tarde, alrededor de sesenta pescadores del archipiélago de Las Guaitecas se tomaron el aeródromo de Melinka, mostrando su profundo rechazo a la ley de pesca y exigiendo el alza de las cuotas de captura, además de la presencia de la intendenta de Aysén, Pilar Cuevas, y del subsecretario de Pesca, Pablo Galilea.

Luego de este suceso, distintas localidades de la región fueron simpatizando con el movimiento y sumándose a la lucha. En Caleta Andrade los habitantes se tomaron el aeródromo; en Coyhaique hubo manifestaciones durante la noche; un grupo aproximado de doscientas personas salió a las calles, levantó barricadas en distintos sectores de la ciudad y se produjeron apagones. Para el día 17 de febrero, casi la totalidad de la región estaba movilizada; la ruta que une Villa Mañihuales con Puerto Aysén estaba bloqueada, el cruce del camino Coyhaique-Chile Chico y Cochrane fue interrumpido por los(as) habitantes de Puerto Guadal, y la carretera hacia Puerto Chacabuco seguía con barricadas. En distintos sectores de la región, como en Chile Chico, se realizaron marchas en solidaridad con la movilización de Puerto Aysén, las que se extendieron también a Punta Arenas y Santiago.

Entre las demandas más importantes que desarrollaron la Asamblea Ciudadana y el Movimiento Social por Aysén, que agrupan a diversas organizaciones sociales, podemos destacar:

- La rebaja sustancial de los combustibles: leña, gas, petróleo, parafina, bencina.

- Salud de calidad.

- Equidad laboral.

- Participación ciudadana vinculante.

- Empoderamiento de la pesca artesanal regional.

- Subsidio al transporte e integración física.

- Regionalización de recursos naturales. 
- Universidad estatal regional.

El conflicto de Aysén evidencia un proceso de pluralidad y transversalidad. En este contexto, una ciudadanía postergada en cuanto a prestaciones de salud, educación y costo de la vida convergió con organizaciones sindicales, movilizadas debido a la coyuntura particular de la disminución en las cuotas de pesca artesanal. También se sumaron redes trasnacionales de defensa del ambiente, como "Patagonia sin represas", que durante el año 2011 había generado movilizaciones en distintas partes de Chile contra el proyecto "HidroAysén" (Romero, 2014; Fuenzalida \& Quiroz, 2012), reactivando el tejido social. A todo ello se sumaron actores tradicionales como la Central Unitaria de Trabajadores (CUT) y la Agrupación Nacional de Empleados Fiscales (ANEF), presentes en todos los conflictos regionales analizados.

\section{Magallanes: una identidad histórica de lucha}

La Región de Magallanes posee una fuerte memoria histórica de lucha social, marcada por hitos como la masacre de la Federación Obrera de Magallanes en 1920, que terminó con el movimiento obrero regional; la creación del primer partido regionalista magallánico en 1931 , y una de las primeras protestas contra la dictadura de Pinochet (el puntarenazo) en febrero de 1984.

Desde sus inicios casi, la identidad magallánica - manifestada a través de distintos diacríticos sociales, como la bandera y el himno- se gestó en un clima adverso (en palabras de magallánicos: "la lucha contra la naturaleza, el viento y frío") y a partir de la interacción de migrantes chilotes, croatas, italianos, ingleses y argentinos. A su vez, el aislamiento -inexistencia de conectividad terrestre con Chile- ha llevado a sus habitantes a generar un mayor vínculo con Argentina, con la que comparten una identidad común patagónica con fuerte interdependencia económica y social.

Tal como ocurre con Arica -y el mayor desarrollo de la ciudad peruana de Tacna-, la región magallánica ha aumentado su sentimiento de postergación debido al desarrollo que han adquirido ciudades de la Patagonia argentina. En esta línea, entre los censos argentinos 2001-2010, las ciudades cercanas del país vecino crecieron más que las magallánicas: El Calafate aumentó demográficamente 159,8\%, desde 6.410 a 16.655 habitantes; Río Gallegos lo hizo en 21\%, de 79.144 a 95.796; y Ushuaia, un $24 \%$, de 45.430 a 56.593 habitantes, lo que ha ido acompaño de mayor desarrollo en infraestructura y servicios. Por su parte, entre los censos de Chile 20022012, Punta Arenas creció solo 10,5\%, de 118.241 a 130.704 habitantes, mientras que Puerto Natales decreció un $-68 \%$ de 18.823 a 18.505 .

Ante tal panorama, los magallánicos manifiestan la ausencia de oportunidades, señalando que la mayoría de los jóvenes debe emigrar a otras regiones para estudiar y trabajar, lo que a su vez evidencia un envejecimiento de la población. Así, mientras en el censo 2002 existían 48 adultos mayores de 60 ańos por cada 100 jóvenes menores de 15 ańos, esa cifra aumentó en 2012 a 72.

El descontento generado por la realidad descrita llevó a que, cuando ENAP (Empresa Nacional del Petróleo) y el gobierno central anunciaron el alza del precio del gas domiciliario en un 16,8\% (principal fuente de combustible), la comunidad magallánica se movilizó transversalmente con la participación de empresarios, sindicatos y organizaciones ciudadanas agrupadas en la Asamblea Ciudadana. 
El conflicto tuvo sus inicios el año 2009, durante el primer gobierno de Bachelet, cuando dirigentes gremiales de Magallanes denunciaron por primera vez el alza histórica del gas domiciliario y comercial. A pesar de que estas acusaciones fueron desmentidas, tuvieron repercusiones en la región, donde se realizaron diversas movilizaciones a fines de ese año.

El 29 de diciembre de 2010, pese al compromiso de campaña, el gobierno de Sebastián Piñera decidió aumentar la tarifa del gas, con el argumento de disminuir la diferencia entre el precio del gas subsidiado que cobra ENAP a la distribuidora Gasco Magallanes y los valores del mercado internacional. Esto, que fue denunciado como un acto injusto, puesto que el $75 \%$ de la producción total del gas extraído en la región es vendido a un menor precio a la empresa transnacional Methanex, de capitales canadienses, desató las críticas y las movilizaciones en las principales ciudades de la región (Punta Arenas y Puerto Natales). A través de la Asamblea Ciudadana de Magallanes se convocó a un paro indefinido, que comenzó en la medianoche del día 11 de enero, noche en que murieron dos mujeres arrolladas por una camioneta. Al día siguiente el paro incluyó a la mayoría de las comunas de la región; hubo cortes de ruta en el camino a Puerto Natales, El Calafate, al aeropuerto, y la movilización se extendió a los principales pasos fronterizos con Argentina. Esta situación tuvo como consecuencia la salida de tres ministros, incluyendo al de Energía, Ricardo Raineri, y desembocó, como acuerdo, en un alza del gas en un 3\% y los subsidios a las 18.000 familias más pobres de la región.

\section{Conclusiones}

Luego del análisis de casos, es posible identificar distintas elementos comunes en la trayectoria de los movimientos regionales.

En primer lugar, se constata la pluralidad y coexistencia de distintos fenómenos al interior de las acciones colectivas. De esta forma, más que clasificar como totalidad el movimiento o la acción colectiva que ha tenido lugar en las regiones entre 2011 y 2013, resulta significativo clasificar discursividades relacionadas con intereses y actores particulares al interior del movimiento. Para tal efecto, cuando una discursividad se hegemoniza y alcanza grados de unidad, es posible clasificar el movimiento en su totalidad; para el resto de los casos, resta la posibilidad de caracterizar discursividades en pugna y asignarles - eventualmente- grados de representatividad intramovimiento.

Desde esta posición, utilizando la tipología de Penaglia (2014), se constató en los movimientos la existencia de "defensa de intereses creados" en luchas egoístas caracterizadas por una menor politización, por la particularidad de la demanda y una mayor cercanía entre actor y beneficio, lo que podría observase en ciertas acciones ligadas a NIMBY y representación contenciosa en Calama, Magallanes, Freirina y Tocopilla. También se constató "defensa colectiva y aislada", principalmente en episodios de violencia espontánea e inorgánica en Magallanes, Aysén y Tocopilla. Finalmente se identificaron discursos ligados a "luchas de transformación social", donde se construyeron relatos en torno a problemáticas estructurales (centralismo, 
sistema impositivo, sistema político, distribución de la riqueza y del poder, entre otros), destacando el caso de Calama, Magallanes y Aysén.

Como es posible ver, muchos de los movimientos son clasificados en más de una tipología, siendo los casos de Magallanes y Calama emblemáticos. En ambos, parte de los relatos del movimiento se estructuraron en torno a intereses inmediatos, generando masividad a partir de demandas cotidianas analizables desde la elección racional: protestas porque el alza del gas afecta el bolsillo y confort de los magallánicos o protestas porque el boom del cobre genera hiperinflación y contaminación en Calama. A la vez, los actores, articulados mayoritariamente en asambleas ciudadanas, construyeron demandas politizadas que incorporaron a sus petitorios. Ejemplo: nacionalización de los recursos naturales.

La coexistencia de fenómenos no solo se manifestó en intereses y politización, sino que también se puede observar en el tipo de estructura adquirida por el movimiento. Así, por un lado se constataron acciones colectivas poco orgánicas y desarticuladas, junto con la acción orgánica y estructurada de distintas ONG, grupos de interés y partidos políticos. Este elemento fue clave para caracterizar tensiones entre "movimientos 2.0" (Castells, 2012; Treré \& Cargnelutti, 2014) -caracterizados por la espontaneidad, indignación, horizontalidad, inorganicidad y el fuerte uso de tecnología y redes sociales- y movimientos tradicionales con características orgánicas. En esta línea, si bien todos los movimientos estudiados se han constituido a partir de asambleas ciudadanas, estas en ciertos casos estuvieron conformadas y lideradas por ciudadanos autónomos, sin la "conducción" de las organizaciones tradicionales; en otros casos se crearon asambleas ciudadanas exclusivamente de organizaciones. Sobre este punto, un elemento clave es el rol que desempeńaron el Partido Comunista y la Central Unitaria de Trabajadores, que participaron en la totalidad de los movimientos, aunque con distintos grados de protagonismo, y siendo parte importante de la tensión entre movimientos $2.0 \mathrm{y}$ movimiento tradicional.

Por otro lado, se evidencia que en la mayoría de los casos el movimiento comenzó como una demanda particular y localizada, generalmente con dos componentes: una dimensión con características NIMBY y la existencia de representación contenciosa - principalmente en los casos del norte-, en que la ciudadanía demanda presencia del Estado en una temática particular (ausencia de agua, malos olores, reconstrucción, falta de apoyo); o en la que líderes políticos comienzan a posicionar demandas en la agenda pública local.

A su vez, en gran parte de los conflictos se observa la presencia de temáticas ambientales (Aysén, Arica, Copiapó), en torno a las cuales las redes trasnacionales o nacionales de defensa han creado estructuras sociales de deliberación ciudadana.

Se constata que las estructuras de movilización primaria-NIMBY, representación contenciosa y redes transnacionales- se enfrentan a un Estado con pocas capacidades institucionales para solucionar el conflicto. Al respecto, en la investigación destaca que desde las intendencias y gobernaciones las estrategias gubernamentales se orientaron a: i) contener y reprimir la protesta social; ii) cooptar y dividir; iii) dilatar en negociaciones extensas, sin generar constructivismo político. En esta línea, destaca que las acciones de protestas más fuertes se han desarrollado en el 
periodo 2011-2013; sin embargo, la totalidad de los conflictos estudiados comenzó con las primeras manifestaciones y acciones antes de 2009.

Los movimientos primarios, independientemente de su éxito o fracaso (capacidad de oponerse a un proyecto), generan la coyuntura para que la ciudadanía se encuentre (espacio público, reconocimiento, deliberación) y descubra que posee problemáticas y causas comunes. En este sentido, los movimientos primarios han servido como estructura sobre la que se construyen nuevos movimientos sociales. Así, la totalidad de los casos estudiados revela sentimientos históricos de postergación y ausencia de soluciones a demandas particulares, lo que, junto con la labor creciente de movimientos primarios destinados a activar el tejido social, desencadenó la formación de asambleas ciudadanas. En ellas el movimiento primario de demandas particulares adquirió una dimensión rizomática y transversal, logrando mayores niveles de politización en un cuestionamiento del modelo de desarrollo, del régimen político, del sistema impositivo $y$, naturalmente, de la incapacidad e injusticia del centralismo en su gobierno de las regiones.

Finalmente, más allá de las continuidades entre movimientos, habiéndose superado la fase primaria -NIMBY, redes trasnacionales ambientalistas o representación contenciosa- y una vez establecida la fase de agregación, con la constitución de movimientos regionales transversales, estos han adquirido distintas formas, entre las que destacan los siguientes:

Movimientos tradicionales de varios puntos: movimientos de este tipo representan mayormente la marginalidad y la postergación. Elaboran demandas amplias que generalmente involucran mayores recursos, infraestructura y capital humano en temas relacionados con la salud, la vivienda, la educación, el empleo, entre otros. Representan acciones colectivas que, aunque manifiestan interesantes procesos de emancipación y lucha, como los de Aysén o Tocopilla, son principalmente peticionistas.

Movimientos contenciosos: estos movimientos son también peticionistas y generalmente presentan demandas mayoritariamente aisladas, pero se diferencian de los "movimientos tradicionales de varios puntos" por ser principalmente defensivos. En esta categoría se estructuran principalmente para la mantención de subsidios y regalías, como en el caso de Magallanes (más allá de los intentos de la Asamblea Ciudadana por levantar demandas de mayor politización).

Demanda por leyes especiales: en este caso se inscriben movimientos como el de Arica o Calama, que buscan la elaboración de políticas reformistas orientadas a conseguir mayor poder y autonomía en los espacios regionales. Este tipo de movimiento es el que plantea un mayor desafío en materia de articulación interterritorios e interconflictos. A su vez, genera mayores tensiones entre demandas maximalistas (de reformas estructurales) y representación contenciosa; por tanto, corre también mayores riesgos de cooptación por parte del poder central, que suele responder a las demandas estructurales con regalías, subsidios, proyectos de inversión y "tratos preferenciales". 


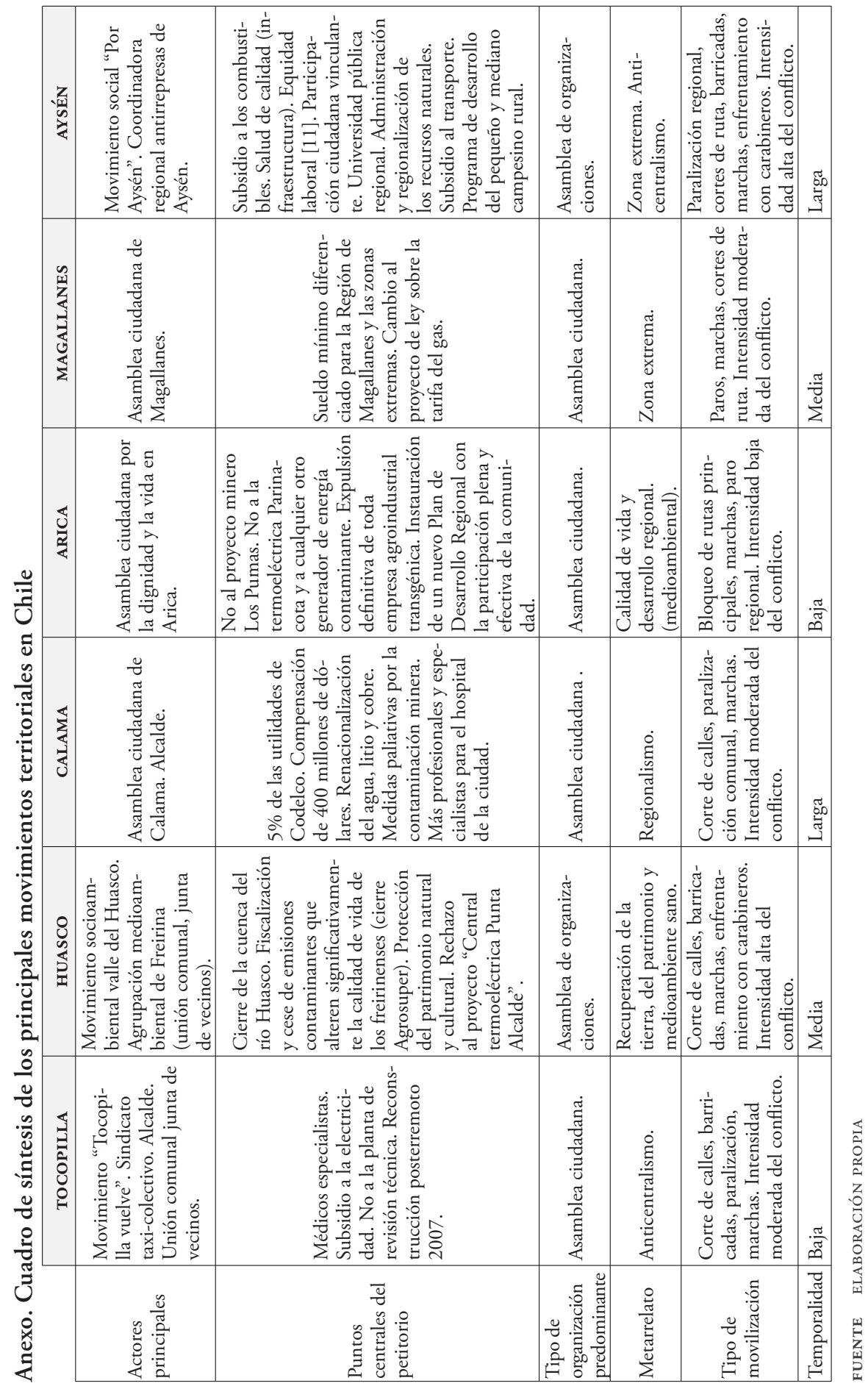




\section{Referencias bibliográficas}

Acosta, A. (2012). Ecuador: del extractivismo al neo-extractivismo. Pueblos. Revista de Información y Debate (50), 23-27. En http://www.revistapueblos.org/old/spip. php?article2361

Aid Camp, R. (2000), La política en México. México, D.F.: Siglo XxI.

Amézaga, I. \& Martí, S. (2012). ¿Existen los Yimbis? Las plataformas de reivindicación territorial en Soria, Teruel y Zamora. Revista Española de Investigaciones Sociológicas, (138), 3-18. En http://www.redalyc.org/articulo.oa?id=99724687001

Arciga, S. (2012). La ciudadanía como arquitectura del pensamiento y la memoria social. Polis, 8(1), 45-64. En http://www.redalyc.org/articulo.oa?id=72623424003

Bahamonde, M. (1977). El caudillo de Copiapó. Santiago: Nascimento.

Benavente, D. (2007). Descentralización: la revolución olvidada. Temuco: Universidad Católica de Temuco.

Blofield, M. (2011). Desigualdad y política en América Latina. Journal of Democracy en Español, 3(julio), 58-74. En http://www.plataformademocratica.org/Publicacoes/21701.pdf

Boisier, S. (2004). Desarrollo territorial y descentralización. El desarrollo en el lugar y en las manos de la gente [versión electrónica]. EURE, 30(90), 27-40. En http://www.scielo. cl/pdf/eure/v30n90/art03.pdf

Boisier, S. (1989). Palimpsesto de las regiones como espacios socialmente construidos. En E. Laurelli \& A. Rofman (Comps.), Descentralización del Estado: Requerimientos y políticas en la crisis (pp. 57-98). Buenos Aires: Fundación Friedrich Ebert/Centro de Estudios Urbanos y Regionales (CEUR).

Boisier, S. (1990). El Mensaje Presidencial al Congreso: una lectura desde las regiones. En S. Boisier \& G. Martínez, (Eds.), Desarrollo y regionalización (pp. 15-41). Santiago: Fundación Libertas.

Boisier, S. (1999). El desarrollo territorial a partir de la construcción de capital sinergético. Revista Estudios Sociales (Corporación de Promoción Universitaria, Chile), (99), 59-80.

Castells, M. (2003). La era de la información: El poder de la identidad (Vol. II). Madrid: Alianza.

Castells, M. (2012). Redes de indignación y esperanza. Los movimientos sociales en la era de Internet. Trad. M. Hernández. Madrid: Alianza Editorial. Versión digitalizada en http://arditiesp.files.wordpress.com/2013/01/castells_redes_indignac_2012.pdf

Cavarozzi, M. (2006). Autoritarismo y democracia. Buenos Aires: Ariel.

Charry, C. (2006). ¿Nuevos o viejos debates? Las representaciones sociales y el desarrollo moderno de las ciencias sociales. Revista de Estudios Sociales (Universidad de Los Andes, Colombia), (25), 81-94. En http://res.uniandes.edu.co/view.php/283/index. php?id=283

Coller, X. (2005). Estudio de Casos. Colección Cuadernos Metodológicos 30. Madrid: Centro de Investigaciones Sociológicas (cIs).

Brading, D. A. (Ed.). (1980). Caudillo and peasant in the Mexican Revolution. Cambridge: Cambridge University Press.

Daitsman, A. (1995). The people shall be all: Liberal rebellion and popular mobilization in Chile 1830-1860. Tesis doctoral, University of Wisconsin-Madison.

Del Alcázar, J. (2006). Historia contemporánea de América. Valencia: Universidad de Valencia. 
Espinoza, V. (2010). Redes de poder y sociabilidad de la élite política chilena. Los parlamentarios 1990-2005. Polis (Revista de la Universidad Bolivariana), 9(26), 251-286. En http:// www.redalyc.org/articulo.oa?id=30515373013

Falleti, V. \& García, V. (2011) Unidad y multitud en los movimientos sociales. Reflexiones a partir de dos casos latinoamericanos. Andamios, 8(15), 305-333. En http://www. redalyc.org/articulo.oa?id=62819892013

Foucault, M. (1979). Microfísica del poder. Ed. y trad. J. Varela \& F. Álvarez-Uría (2ª ed.). Madrid: Ediciones La Piqueta. En http://www.pensamientopenal.com.ar/system/ files/2014/12/doctrina39453.pdf

Fuenzalida, M. \& Quiroz, R. (2012). La dimensión espacial de los conflictos ambientales en Chile. Polis, Revista Latinoamericana, 11(31), 157-168. http://dx.doi.org/10.4067/ S0718-65682012000100009

Gandhi, J. \& Przeworski, A. (2006). Cooperation, cooptation, and rebellion under dictatorships. Economics and Politics, 18(1), 1-26.

Garcés, M. (2012). El despertar de la sociedad. Los movimientos sociales en América Latina y Chile. Santiago: LOM.

Garretón, M. A. (2002). La transformación de la acción colectiva en Latinoamérica. Revista Cepal, (76), 7-24.

Garretón, M. A. (2013). Conflicto Estado-Sociedad y Ciudadania. Conferencia en Instituto Igualdad, Santiago, 2 de octubre de 2013.

Gerschewski, J. (2010). The three pillars of stability. Towards an explanation of the durability of autocratic regimes in East Asia. Trabajo presentado en 106th Annual Meeting of the American Political Science Association (APSA), 2-5 septiembre 2010, Washington, D.c.

Góngora, M. (1981). Ensayo histórico sobre la noción de Estado en Chile en los siglos XIX y XX. Santiago: Ediciones de la Ciudad.

González, S. (2010). Nación, salitre y frontera: Siete momentos clave del proceso de integración de Tarapacá a Chile, 1880-1929. En G. Cid \& A. San Francisco (Eds.), Nacionalismos e identidad nacionalen Chile. Siglo XX (Vol II, pp. 63-106). Santiago: Editorial Bicentenario. En http://www.dt.gob.cl/documentacion/1612/articles-62508_recurso_1.pdf

Gramsci, A. (1988). Antología. Selección, traducción y notas de Manuel Sacristán. Madrid: Siglo XXI.

Grez, S. (2007). Textos. Cyber Humanitatis (41). En http://web.uchile.cl/vignette/ cyberhumanitatis/CDA/indice/0,1495,ISID\%253D730,00.html

Haldenwang, Ch. (1990). Hacia un concepto politológico de la descentralización del Estado en América Latina. EURE, 17(5), 61-77. En http://www.eure.cl/index.php/eure/article/ view/1046

Holloway, J. (2011). Cambiar el mundo sin tomar el poder. El significado de la revolución hoy. Santiago: LOM.

Illanes, M. A. (1992). La dominación silenciosa: productores y prestamistas en la minería de Atacama. Chile 1830-1860. Santiago: Instituto Profesional Blas Cañas.

Illanes, M. A. (1993). El proyecto comunal en Chile (Fragmentos): 1810-1891. Historia (Instituto de Historia, Pontificia Universidad Católica de Chile), (27), 213-320. [Versión en línea], http://revistahistoria.uc.cl/estudios/3158/ 
Klein, J. (2005). Iniciativa local y desarrollo: respuesta social a la globalización neoliberal [versión electrónica]. EURE, 31(94), 25-39. http://dx.doi.org/10.4067/S025071612005009400002

Laclau, E. \& Mouffe, Ch. (1986). Hegemonía y estrategia socialista. Hacia una radicalización de la democracia. México, D.F.: Fondo de Cultura Económica.

Latinobarómetro (Corporación). (2011). Informe 2011. Santiago: Latinobarómetro. En http:// www.infoamerica.org/primera/lb_2011.pdf

Lechner, N. (1984). La conflictiva y nunca acabada construcción del orden deseado. Santiago: Flacso-Chile. Versión digitalizada en http://flacsochile.org/biblioteca/pub/ publicos/1984/libro/000043.pdf

Lefebvre, H. (1969). El derecho a la ciudad. Madrid: Península.

Lewis, S. E. (1994). Myth and the history of Chile's Araucanians. Radical HistoryReview, (58), 113-141. doi:10.1215/01636545-1994-58-113

Marimán, J. (2012). Autodeterminación. Santiago: LOM.

Martinic, M. (1992). Historia de la Región Magallánica. 2 tomos. Punta Arenas: Universidad de Magallanes.

Martner, G. (1993). Descentralización y modernización del Estado en la transición. Santiago: LOM.

Marx, K. \& Engels, F. (2006, original 1848). Manifiesto Comunista. Santiago: Quimantú.

Mayol, A. (2013). El derrumbe del modelo. La crisis de la economía de mercado en el Chile contemporáneo. Santiago: LOM.

Melucci, A. (1999). Acción colectiva, vida cotidiana y democracia. México, D.F.: El Colegio de México, Centro de Estudios Sociológicos.

Michels, R. (1962). Los partidos politicos: Un estudio sociológico de las tendencias oligárquicas de la democracia moderna. Buenos Aires: Amorrortu.

Moulian, T. (1993). La forja de ilusiones: El sistema de partidos 1932-1973. Santiago: ArcisFlacso.

Moulian, T. (2006). Fracturas: de Pedro Aguirre Cerda a Salvador Allende (1938-1973). Santiago: LOM.

Moulian, T. (2009). Contradicciones del desarrollo politico chileno, 1920-1990. Santiago: LOM.

Moreno, E. (2010). El aeropuerto y el movimiento social de Atenco. Convergencia. Revista de Ciencias Sociales, 17(52), 79-96. En http://www.redalyc.org/articulo. oa?id=10512246004

Moriconi, M. (2009). El malestar social y la víctima-cómplice. Polis, 5(1), 115-142. En http:// dialnet.unirioja.es/servlet/articulo?codigo $=3097856$

Nickson, A. (1995). Local government in Latin America. Boulder, co: Riemer.

Nun, J. (1987). Gramsci y el sentido común. Revista Mexicana de Sociología, 49(2), 21-54. doi: $10.2307 / 3540462$

Organización para la Cooperación y el Desarrollo Económicos (OCDE). (2013). Estudios de politica urbana de la OCDE Chile. Santiago: Subsecretaría de Desarrollo Económico (SUDERE).

Panfichi, A. (2011). Contentious representation in contemporary Peru. En J. Crabtree (Ed.), Fractured politics: Peruvian democracy past and present (pp. 89-104). Londres: Institute for the Study of the Americas, University of London. En http://bit.ly/1FLlkfh 
Panizza, F. (Comp.). (2009). El populismo como espejo de la democracia. Buenos Aires: Fondo de Cultura Económica.

Penaglia, F. (2012). Una mirada al conflicto en Latinoamérica. Polítika (diciembre 2012).

Penaglia, F. (2014). Teorética de la acción colectiva politizada. Prezi, 27 de junio de 2014, https://prezi.com/ifb67olsgfc1/untitled-prezi/

Penaglia, F. \& Valenzuela, E. (2014). Rebeldía en Calama: desafío al orden centralista chileno en un contexto de boom minero. Revista Mexicana de Ciencias Politicas y Sociales, 59(222), 161-186. En http://www.redalyc.org/articulo.oa?id=42131768007

Ramos, M. L. (1997). La dimensión política de los movimientos sociales: algunos problemas conceptuales. Reis: Revista española de investigaciones sociológicas, (79), 247-263. En http://dialnet.unirioja.es/servlet/articulo?codigo $=760097$

Rauber, I. (2003). América Latina. Movimientos sociales y representación politica. Trad. Darío Machado. Buenos Aires: Central de Trabajadores Argentinos (CTA) y Pasado y Presente xxI. En http://www.rebelion.org/docs/4518.pdf

Ravilla, M. (1996). El concepto de movimiento social: acción, identidad y sentido. Última Década (Revista del Centro de Investigación y Difusión Poblacional de Achupallas, Viña del Mar), (005), 1-18. En http://www.ses.unam.mx/docencia/2014II/Revilla_ ElConceptoDeMovimientoSocial.pdf

Réserve, R. (2004). Los otros actores políticos de la campańa electoral. Realidad (99), 299-315. En http://dialnet.unirioja.es/servlet/articulo? codigo $=4025849$

Retamozo, M. (2009). Las demandas sociales y el estudio de los movimientos sociales. Cinta de Moebio, (35), 110-127. En http://www.facso.uchile.cl/publicaciones/moebio/35/ retamozo.html

Rivera, C. (2010). Internacionalización de movimientos sociales. ¿¿Cuán efectivas son las redes transnacionales de apoyo? Papel Político,15(2), 617-636. En http://www.redalyc.org/ articulo.oa?id=77721289009

Rivera, C. (2011). Conflictos ambientales y redes transnacionales de defensa en el Chile postdictadura. Revista de Ciencias Sociales (Ve), 17(2), 231-246. En http://www. redalyc.org/articulo.oa?id=28022757004

Romero Toledo, H. (2014). Ecología política y represas: elementos para el análisis del Proyecto HidroAysén en la Patagonia chilena. Revista de geografía Norte Grande, (57), 161-175. http://dx.doi.org/10.4067/S0718-34022014000100011

Sabatini, F. \& Wormald, G. (2004). La guerra de la basura de Santiago: desde el derecho a la vivienda al derecho a la ciudad. EURE, 30(91), 67-86. http://dx.doi.org/10.4067/ S0250-71612004009100005

Salazar, G. (1994). L. E. Recabarren y el municipio en Chile (1900-1925). Revista de Sociología (Universidad de Chile), (9), 61-82.

Salazar, G. (2005). Construcción de Estado en Chile (1760-1860): democracia de "los pueblos", militarismo ciudadano, golpismo oligárquico. Santiago: Editorial Sudamericana.

Salazar, G. (2006). La violencia politica popular en las "Grandes Alamedas". Santiago: LOM.

Salazar, G. (2011). En el nombre del Poder Popular Constituyente (Chile, siglo XXI). Santiago: LOM.

Salazar, G. (2013). Movimientos sociales en Chile. Santiago: Uqbar.

Santamarina, B. (2008). Movimientos sociales: una revisión teórica y nuevas aproximaciones. Boletín de Antropología (Universidad de Antioquia, Colombia), 22(39), 112-131. En http://www.redalyc.org/articulo.oa?id=55711908005 
Scribano, A. et al. (2012). Actuel Marx Intervenciones $N^{\circ} 13$. Movimientos Sociales, Populares y Sindicales. Santiago: LOM.

Solimano, A. (2010). Desigualdad económica y contrato social: La experiencia chilena. Revista de Estudios Parlamentarios/Academia Parlamentaria/Cámara de Diputados, 1(2), 139-154.

Tassin, E. (2012). De la subjetivación política. Althusser/Ranciere/Foucault/Arendt/Deleuze. Revista de Estudios Sociales (Bogotá), (43), 36-49. http://dx.doi.org/10.7440/ res43.2012.04

Tironi, E. (2008). La cohesión social latinoamericana. Santiago: Uqbar.

Touraine, A. (1997). ¿Podemos vivir juntos? México, D.F.: Fondo de Cultura Económica.

Toro, N. (2011). Estrategias de las redes transnacionales de defensa. El caso del pueblo indígena Mapuche frente a la construcción hidroeléctrica Ralco en Chile (1996-2000). Tesis de grado, Universidad Colegio Mayor de Nuestra Señora del Rosario, Bogotá. En http:// hdl.handle.net/10336/2382

Treré, E. \& Cargnelutti, D. (2014). Movimientos sociales, redes sociales y Web 2.0: el caso del Movimiento por la Paz con Justicia y Dignidad. Communication \& Society/ Comunicación y Sociedad, 27(1), 183-203. En http://dialnet.unirioja.es/servlet/ articulo? codigo $=4641023$

Tricot, T. (2013). Autonomía. Santiago: Ceibo.

Valenzuela, A. (1977). Political brokers in Chile: Local government in a centralized polity. Durham, NC: Duke University Press.

Valenzuela, E. (1999). Alegato histórico regionalista. Santiago: Ediciones sur.

Valenzuela, E. (2007). Chile duro: Presicracia centralista impuesta por la dictadura derechista y administrada por la centroizquierda paternalista. En F. Carrión, Descentralización en Ecuador: opciones comparadas (pp. 119-142). Quito: Flacso-Ecuador.

Valenzuela, E. (2008). La voz terrible. Infante y el Valdiviano Federal. Santiago: Universidad Bolivariana.

Véliz, C. (1984). La tradición centralista de América Latina. Barcelona: Ariel.

Villalobos, S. (1989). Portales: una falsificación histórica. Santiago: Andrés Bello.

Vitale, L. (1971). Las guerras civiles de 1851 y 1859 en Chile. Serie Historia Social. Concepción: Universidad de Concepción.

Wright Mills, Ch. (1957). La élite del poder. México, D.F.: Fondo de Cultura Económica.

Zeitlin, M. (1984). The civil wars in Chile. Princeton, No: Princeton University Press. 